\title{
Description of a new species of Forcipomyia (Euprojoannisia) Brèthes, 1914 (Diptera: Ceratopogonidae) and a key to Chinese species of the subgenus
}

\author{
Xiao-Jing Han", Xiao-Fei Li", Qiong-Qiong Chang \& Xiao-Hui Hou*
}

\begin{abstract}
Han, X. J., Li, X. F., Chang, Q. Q. \& Hou, X. H. 2017: Description of a new species of Forcipomyia (Euprojoannisia) Brèthes, 1914 (Diptera: Ceratopogonidae) and a key to Chinese species of the subgenus. - Entomol. Fennica 28: 107-112.
\end{abstract}

Forcipomyia (Euprojoannisia) coronacella Han et Hou sp. n. (Diptera: Ceratopogonidae) is described and illustrated based on male specimens from China. The new species is compared with the similar congeners, $F$. (Euprojoannisia) palustris (Meigen, 1804) and F. (Euprojoannisia) mucronis Liu et Yu, 2001. We provide separate keys for identification of the males and females of the species of the subgenus $F$. (Euprojoannisia) Brèthes in China.

X. J. Han, X. F. Li, Q. Q. Chang \& X. H. Hou, Zunyi Medical University, No. 201 Dalian Road, Zunyi, Guizhou Province 563000, China; *Corresponding author's e-mail: hxh19801122@163.com." Equal contribution

Received 14 April 2016, accepted 23 February 2017

\section{Introduction}

Forcipomyia Meigen (Diptera: Ceratopogonidae), a genus with a worldwide distribution, is one of the species-richest in the biting midges, with many species being important pollinators of tropical and subtropical cultivated plants (Young 1986, Martínez et al. 2000). The genus comprises 1,186 species (1,154 extant and 32 fossil) (Borkent 2016). To date, in the subgenus F. (Euprojoannisia) Brèthes 27 species have been recorded in China (Liu \& Yu 2005, Yu \& Song 2008, this paper). Most species of the subgenus F. (Euprojoannisia) Brèthes have eyes bare (only a few species with numerous interommatidial spicules) and contiguous. Palpus of the $3^{\text {rd }}$ segment is with a small sensory pit (a few species with a sacculate sensory pit or none). The aedeagus is triangular, mound-shaped or square, with finger-like, stout or teeth-shaped processes. Paramere is U-shaped or angular, with or without a process on the distal lateral arm and outside the lateral angle.
During the past three years, several entomological surveys of the Tianmushan National Nature Reserve and Qinling Mountains were undertaken, which resulted in a large series of midges deposited in the Insect Collection of Zunyi Medical University (China). We examined ceratopogonid specimens and found two male specimens of the genus Forcipomyia, belonging to an undescribed species of the subgenus Euprojoannisia. The purpose of this paper is to describe and illustrate this new species from China and compare it with morphologically similar species, as well as to provide separate identification keys to males and females of the species of the subgenus Euprojoannisia from China.

\section{Materials and methods}

The specimens of the new species described herein were collected by a Malaise trap in Tianmushan National Nature Reserve $\left(30^{\circ} 20^{\prime} \mathrm{N}\right.$, 
Table 1. Diagnostic features distinguishing Forcipomyia (E.) coronacella Han et Hou sp. n., Forcipomyia (E.) mucronis Liu et Yu, 2001 and Forcipomyia (E.) palustris (Meigen, 1804).

\begin{tabular}{|c|c|c|c|}
\hline Structure & coronacella sp. n. & palustris & mucronis \\
\hline Aedeagus & $\begin{array}{l}\text { Helmet-like, with a } \\
\text { round and smooth } \\
\text { process in middle } \\
\text { (Fig. } 2 \text { b) }\end{array}$ & $\begin{array}{l}\text { Raft-like, with } \\
\text { shallow excavation in } \\
\text { middle, distinctly } \\
\text { sclerotized at apex }\end{array}$ & $\begin{array}{l}\text { Mound-like, with a } \\
\text { columnar and truncate } \\
\text { structure in middle, } \\
\text { with many small teeth } \\
\text { at apex (Fig. 3a) }\end{array}$ \\
\hline Parameres & $\begin{array}{l}\text { Angular, with } 2 \\
\text { small processes on } \\
\text { base and } 2 \text { teeth-like } \\
\text { processes on lateral } \\
\text { arm near middle } \\
\text { (Fig. 2c) }\end{array}$ & $\begin{array}{l}\text { Angular, with } 2 \text { large } \\
\text { processes on base and } \\
2 \text { sting-like processes } \\
\text { on lateral arm near } \\
\text { apex }\end{array}$ & $\begin{array}{l}\text { U-shaped and smooth, } \\
\text { without any processes } \\
\text { on lateral arm (Fig. 3b) }\end{array}$ \\
\hline
\end{tabular}

$\left.119^{\circ} 25^{\prime} \mathrm{E}\right)$, Zhejiang Province and by an insect net in Taibai, Qinling Mountains (34ำ' N, $107^{\circ} 53^{\prime}$ E), Shaanxi Province, China. The specimens were mounted in phenol-balsam and examined as described by Wirth and Marston (1968) and Liu and $\mathrm{Yu}$ (2005). The type specimens are deposited in the Insect Collection of Zunyi Medical University, Zunyi, Guizhou Province, China (ICZU).

The morphological terminology and identification methods used in the study follow McAlpine et al. (1981), Liu et al. (2001), Spinelli et al. (2005) and Liu \& Yu (2005). Diagnostic characters were illustrated using a Leica MZ 12.5 stereomicroscope. The measurements of the wings, the flagellomeres 1-13, the segments of the palpus and the segments of the legs are in millimeters $(\mathrm{mm})$. The following abbreviations are used:

$-\quad \mathrm{AR}=$ Antennal ratio (the ratio of the lengths of the segments $11-15$ and 3-10)

- $P R=$ Palpus ratio (the ratio of the length and width of the $3^{\text {rd }}$ segment)

- $\mathrm{TR}=$ Tarsus ratio (the ratio of the lengths of the $1^{\text {st }}$ and $2^{\text {nd }}$ segment)

- $\mathrm{F}-\mathrm{T}=$ Femur-tibia-tarsus ratio (the ratios of the lengths of femur, tibia, and the $1^{\text {st }}-5^{\text {th }}$ segments of the tarsus)

- $\mathrm{CR}=$ The ratio of the lengths of costa and the wing

\section{Taxonomy}

\subsection{Description of Forcipomyia \\ (Euprojoannisia) coronacella Han et Hou sp. n. (Figs 1-2)}

Material examined. Holotype: adult male, Taibaishan National Forest Park, Shaanxi Province, China, 16.VII.2012, Lv Bin leg. (ICZU)

Paratype: 1 adult male, Tianmushan National Nature Reserve, Zhejiang Province, China, 1.IX. 2012, Han Xiaojing leg. (ICZU)

Diagnosis. The new species is most closely similar to Forcipomyia (Euprojoannisia) mucronis Liu et Yu, 2001 and Forcipomyia (Euprojoannisia) palustris (Meigen, 1804), which are distributed in Luding county, Sichuan province, China. The main differentiating characters of these three species are shown in Table 1.

Description. Male. Head brown, vertex with numerous brown hairs. Eyes (Fig. 1d) contiguous. Antennal flagellum (Fig. 1a) with lengths of flagellomeres $1-13$ in proportion of 16:11:11: 11:11:11:12:12:12:38:25:21:21, AR 1.23 (1.12$1.36, n=2)$, distal four segments elongated, segment 13 parallel-sided with terminal nipple. Palpus (Fig. 1b) with lengths of segments in proportion of $6: 6: 12: 6: 6 ; 3^{\text {rd }}$ segment slender and swollen at the basal $1 / 2$; sensory pit small, situated in front of swollen portion; $4^{\text {th }}$ and $5^{\text {th }}$ segment almost fused; PR 3.77 ( $n=2)$.

Thorax. Brown. Scutum dark brown, without pattern. All legs pale. Foreleg with lengths of F-T in proportion of 29:21:11:6:6:5:-, prothoracic TR 
Fig. 1. Forcipomyia (Euprojoannisia) coronacella Han et Hou sp. n., male. - a. Antenna. -b. Palpus. - c. Wing. - d. Eyes.
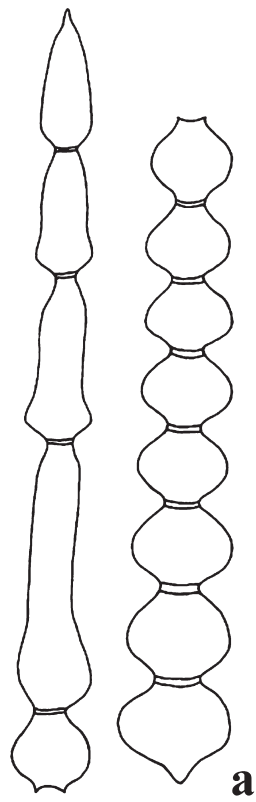

$1.83(n=2)$; midleg with lengths of $\mathrm{F}-\mathrm{T}$ in proportion of 35:30:8:6:6:5:-, mesothoracic TR 1.23 $(n=2)$; hindleg with lengths of $\mathrm{F}-\mathrm{T}$ in proportion of 30:30:11:6:6:5:-, metathoracic TR $1.75(n=1)$; claws slender, curved; empodia present; hind tibia with 6 terminal bristles, without ctenidial comb. Wing (Fig. 1c) pale, no spots, with dense macrotrichia; wing length $0.84 \mathrm{~mm}(0.8-0.88$ $\mathrm{mm}, n=2)$, breadth $0.32 \mathrm{~mm}(0.3-0.33 \mathrm{~mm}, n=2)$; CR $0.43(0.42-0.44, n=2)$. Halter pale.

Abdomen. Light brown, with short appressed hairs and long semierect hairs. Genitalia (Fig. 2a): tergite 9 short, not extending to apex of gonocoxite, posterior margin rounded; sternite 9 broad, posterior margin transverse. Gonocoxite moderately stout, about 2 times longer than the
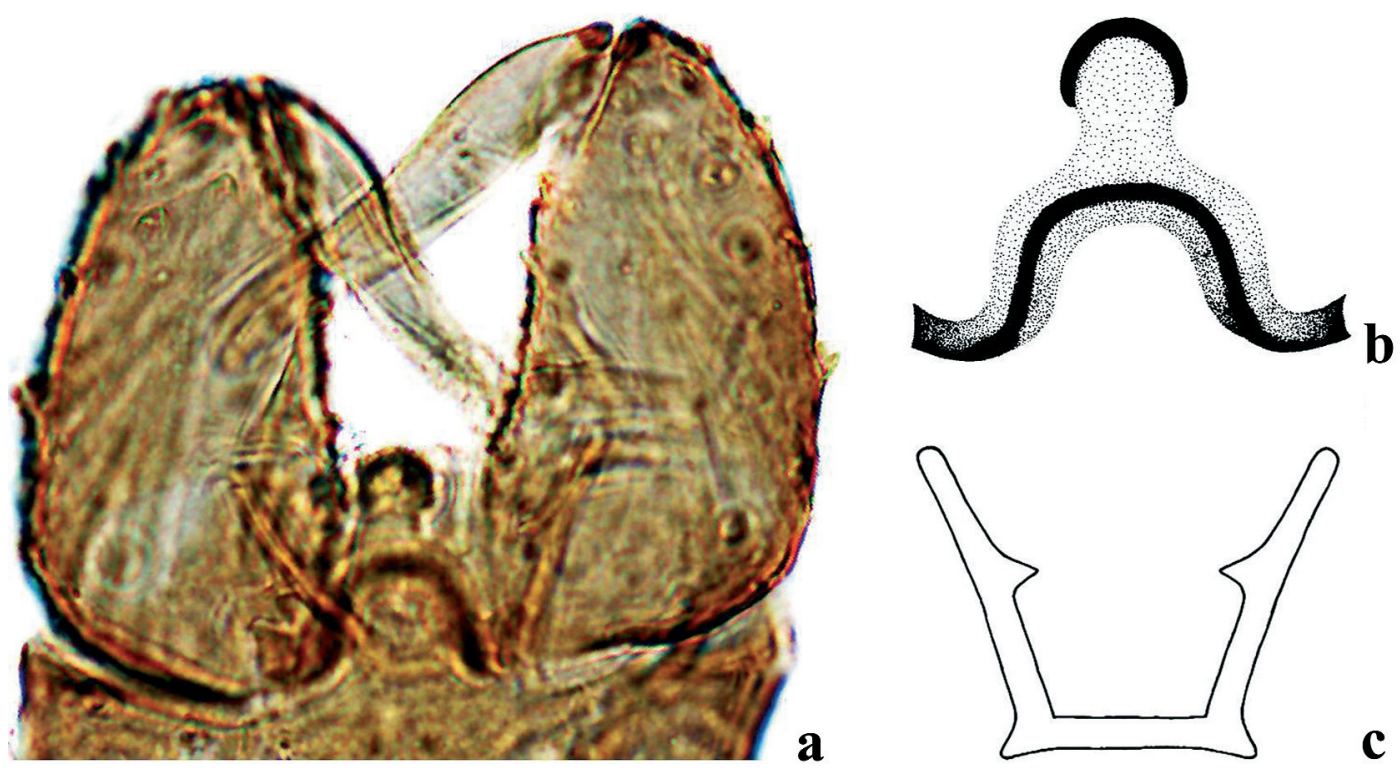

Fig. 2. Forcipomyia (Euprojoannisia) coronacella Han et Hou sp. n., male. - a. Genitalia, ventral view.

- b. Aedeagus. - c. Paramere. 
greatest width; gonostylus pale, nearly straight, tip barely curved. Aedeagus (Fig. 2b) helmetlike, with bell-shaped on outline, one distal rounded and blunt process, $1 / 3$ of height and 1/4 of width of whole aedeagus, sclerotized arch high; parameres (Fig. 2c) U-shaped, bottom flat, bottom angular between side arms and arch, with two processes on lateral arm near middle.

Female. Unknown.

Etymology. The species is named after the characteristic shape of its aedeagus, which is helmet-like.

Distribution. China (Zhejiang and Shaanxi Provinces).

\subsection{Key to females of the species of the subgenus $F$. (Euprojoannisia) from China}

1. With 1 spermatheca

- With 2 spermatheca

2. Spermatheca with a curved neck, neck length more than $1 / 2$ of that whole spermatheca; tarsal ratio $\left(\mathrm{T}_{1} / \mathrm{T}_{2}\right)$ of mesothoracic legs more than 1.80 F. bahelea Liu et Yu

- Spermatheca with straight neck, neck length less than $1 / 3$ of that spermatheca; tarsal ratio $\left(\mathrm{T}_{1} / \mathrm{T}_{2}\right)$ of mesothoracic legs less than $1.00 \quad 3$

3. $3^{\text {rd }}$ segment of palpus swollen significantly, with a deep and sacculate sensory pit

F. tonicus Liu et $\mathrm{Yu}$

- $3^{\text {rd }}$ segment of palpus slender, with a shallow sensory pit F. lingnanensis Liu et $\mathrm{Yu}$

4. Metathoracic TR>2.50; sizes of two spermatheca unequal F. balteatus Liu et $\mathrm{Yu}$

- Metathoracic TR<1.80; two spermatheca equal-sized or unequal

5. Prothoracic $\mathrm{TR}>1.70 ; \mathrm{AR} \geq 1.20$

- Prothoracic TR $<1.60 ; \mathrm{AR}<1.10$

6. $3^{\text {rd }}$ segment of palpus with a lar sensory pit; subgenital plate arch-shaped, simple; sizes of two spermatheca unequal, with a short neck F.centrosus Liu et $\mathrm{Yu}$

- $3^{\text {rd }}$ segment of palpus with a small and shallow sensory pit; subgenital plate arch-shaped, with distinctly sclerotized band on outside of basal arms; spermatheca sizes equal, with long neck F. ignobilis Liu et $\mathrm{Yu}$

7. $1^{\text {st }}$ tarsal segment of hindleg with rows of feather-like bristles $-1^{\text {st }}$ tarsal segment of hindleg without rows of feather-like bristles

8. Spermatheca with long and swollen neck, width $>60 \mathrm{~mm} \quad$ F.psilonota (Kieffer)

- Spermatheca with short neck, width $<50 \mathrm{~mm}$ F. minor Liu, Yan et Liu

9. Large species (wing length $1.20 \mathrm{~mm}$ ); width of smaller spermatheca $<30 \mathrm{~m} ; \mathrm{PR}>3.5$

F. largus Liu et $\mathrm{Yu}$

- Small species (wing length $0.77 \mathrm{~mm}$ ); width of smaller spermatheca $\geq 40 \mathrm{~m} ; \mathrm{PR}<2.5$

F. pipiens Liu, Yan et Liu

\subsection{Key to males of the species of the subgenus $F$. (Euprojoannisia) from China}

1. Aedeagus triangular, with cap-shaped, fingerlike structure or nothing on distal end 2

- Aedeagus non-triangular 13

2. Aedeagus with triangular and sclerotized structure on distal end 3

- Aedeagus with finger-like structure on distal end

3. $9^{\text {th }}$ sternite as long as wide; $9^{\text {th }}$ tergite approximately triangular

F. appendicular Liu, Yan et Liu

$9^{\text {th }}$ sternite two times as wide as long; shape of $9^{\text {th }}$ tergite semicircle F.psilonota (Kieffer)

4. Aedeagus with teeth-like or pointed structure near end

- Aedeagus without above structure 7

5. Aedeagus with 2 finger shaped processes near end, directed to the base

F. pennielongata Chan et LeRoux

- Aedeagus with 1 or 5 teeth-like processes on both sides of distal end

6. Aedeagus with 5 minor teeth-like processes on both sides of distal end; parameres without a process on distal end, parameres swollen on middle of side arms

F. calamistrata Debenham et Wirth

- Aedeagus with a small and acute process on both sides of distal end; parameres with a process on distal end of side arms, swollen on middle of side arms $\quad$ F. yoshimurai Tokunaga

7. Parameres without process on base arm; $9^{\text {th }}$ tergite approximately triangular, equal length with coxite

\section{3}

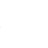

4


- Parameres with 2 processes on both ends of base arm; $9^{\text {th }}$ tergite non-triangular, with length less than $1 / 2$ of coxite

8. $3^{\text {rd }}$ segment of palpus without a sensory pit

F. separatus Liu, Yan et Liu

$-3^{\text {rd }}$ segment of palpus with a sensory pit F. yapensis Tokunaga et Murachi

9. Parameres with U-shaped bottom flat, a pair of clear processes on outside lateral angle 10

- Parameres with U-shaped bottom flat or curved, without a process on outside lateral angle

11

$10.9^{\text {th }}$ sternite with excavation posterio-medially; coxite short and stout, 1.5 times as long as wide; aedeagus with blunt end

F. mesasiatica Remm

- $9^{\text {th }}$ sternite with shallow depression posteriomedially; coxite 2.0 times as long as wide; aedeagus with hook-shaped end

F. chongmingensis Liu et $\mathrm{Yu}$

11. Aedeagus small and short, without sclerotized basal arch

F. astyla Tokunaga

- Aedeagus with well sclerotized basal arch 12

$12.9^{\text {th }}$ sternite with a bump medially and sclerotized on both sides at posterior; aedeagus with basal arms arched

F. deformis Liu et $\mathrm{Yu}$

- $9^{\text {th }}$ sternite with excavation medially at posterior, not sclerotized; aedeagus with basal arms clearly curved

F. claudus Liu et Yu

13. Aedeagus with apex depressed and sclerotized

- Aedeagus with a globular, columnar and finger-shaped process at apex

14. Parameres with U-shaped bottom flat, 2 processes on distal lateral arm

F. palustris (Meigen)

- Parameres with U-shaped bottom curved, without a process on distal lateral arm

F. ratis Liu et $\mathrm{Yu}$

15. Aedeagus with 1 or 2 slender and finger-like processes at apex

- Aedeagus bell-shaped on outline, with a stout structure in middle, obtuse or truncate at apex

16. $9^{\text {th }}$ sternite with a shallow depression posterio-medially; $9^{\text {th }}$ tergite $1 / 3$ times as long as coxite; aedeagus with a pair of long and fin-
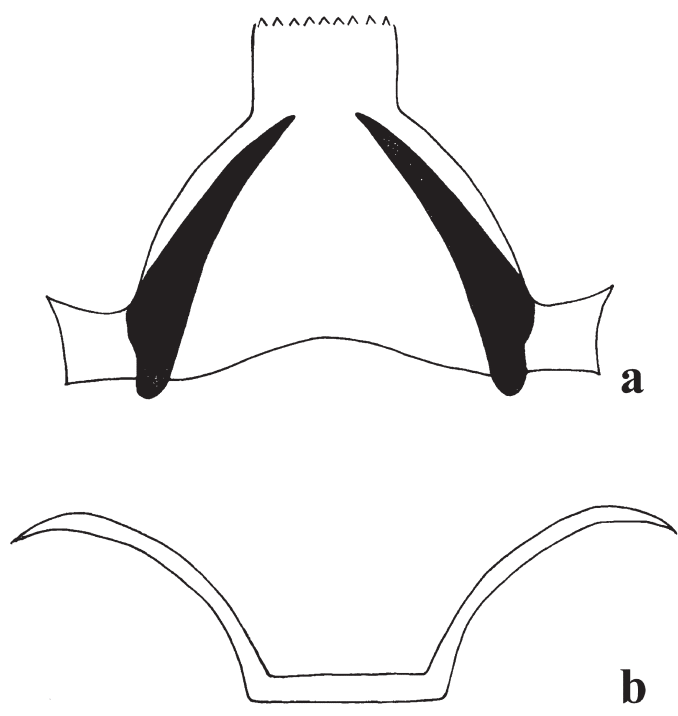

Fig. 3. Forcipomyia (Euprojoannisia) mucronis Liu et Yu, male. - a. Aedeagus. - b. Paramere. (After Liu et al. 2001)

ger-like processes at apex; parameres Ushaped, without any processes

F. picturatus Liu et $\mathrm{Yu}$

- $9^{\text {th }}$ sternite curved posteriorly; $9^{\text {th }}$ tergite $2 / 3$ times as long as coxite; aedeagus with a small and finger-like process at apex medially; parameres angular, with 2 processes on lateral arm near apex

F. amiantos Yu et Song

17. Aedeagus mound-like, with a columnar and truncate process in middle, with many small teeth at apex; parameres U-shaped, without any processes on lateral arm

F. mucronis Liu et $\mathrm{Yu}$

- Aedeagus helmet-like, with a round and smooth process in middle; parameres between side arms and arch bottom angular, with 2 processes on lateral arm near middle

F. coronacella Han et Hou sp.n.

Acknowledgments. We cordially thank Prof. Yi-Xin Yu (Academy of Military Medical Sciences, Beijing, China) for his invaluable advice and comments on the draft of the manuscript. This study was financially supported by the grant from the National Natural Science Foundation of China (No. 81360257), the Science and Technology Fund Project of Guizhou (No. LKZ [2011] 39), the Program for Innovative Research Team in Zunyi City (No. ZSKH201540) and the visiting scholar of western light Project. 


\section{References}

Borkent, A. 2016: World species of biting midges (Diptera: Ceratopogonidae). http://wwx.inhs.illinois.edu/files/ 8413/4219/9566/CeratopogonidaeCatalog.pdf (updated 16-VI-2016).

Brèthes, J. 1914: Descripcion de six Cécidomyidae (Dipt.). - Anales del Museo Nacional de Buenos Aires 26: 151-156.

Liu, J. H., Yan, G., Liu, G. P., Hao, B. S., Liu, Z. J. \& Yu, Y. X. 2001: Forcipomyiinae of China (Diptera: Ceratopogonidae) II. The genus Forcipomyia Meigen. - In: Zhang, Z. Q. (ed.), Fauna of China II: 161-176. Magnolia Press, Bellevue WA. 176 pp.

Liu, J. H. \& Yu, Y. X. 2005: Forcipomyiinae, Forcipomyia Meigen, 1818. - In: Yu, Y. X. (ed.), Ceratopogonidae of China (Insecta, Diptera): 468-692. Military Medical Science Press, Beijing. 1699 pp.

Martínez, A., Narváez, Z. \& Spinelli, G. R. 2000: Mosquitas polinizadoras (Diptera: Ceratopogonidae) del cacao colectadas en comunidades Piaroa en Amazonas,
Venezuela. - Boletín de Entomología Venezolana 15: 249-253.

McAlpine, J. F., Peterson, B. V., Shewell, G. E., Teskey, H. J., Vockeroth, J. R. \& Wood, D. M. 1981: Manual of Nearctic Diptera. - Agriculture Canada Monograph, Ottawa 27: 674.

Spinelli, G. R., Ronderos, M. M., Diaz, F. \& Marino, P. I. 2005: The bloodsucking biting midges of Argentina (Diptera: Ceratopogonidae). - Memorias Do Instituto Oswaldo Cruz 100: 137-150.

Wirth, W. W. \& Marston, N. 1968: A method for mounting small insects on microscope slides in Canada Balsam. - Annals of the Entomological Society of America 61: 783-784.

Young, A. M. 1986: Notes on the distribution and abundance of midges (Diptera: Ceratopogonidae and Cecidomyiidae) in some Central American cacao plantations. - Brenesia 24: 273-286.

Yu, Y. X. \& Song, F. C. 2008: A new subgenus, two new species of Forcipomyia from China (Diptera, Ceratopogonidae). - Acta Zootaxonomica Sinica 33: 793 795. 